\title{
Gamma Knife surgery for hemifacial spasm related to cerebellopontine angle tumors
}

\author{
Clinical article \\ Cheng-Siu Chang, M.D., ${ }^{1,3}$ Chun-Chao Chuang, M.D., ${ }^{2,5}$ Ming-Fan Wu, M.D., ${ }^{1,4}$ \\ Wen-Shan Liu, M.D., ${ }^{1,6}$ Hsien-Tang Tu, B.S., ${ }^{8}$ and Chuan-Fu Huang, M.D., Ph.D. ${ }^{7,8}$ \\ ${ }^{1}$ School of Medicine and ${ }^{2}$ School of Medical Imaging and Radiological Sciences, Chung Shan Medical \\ University; Departments of ${ }^{3}$ Neurosurgery, ${ }^{4}$ Medical Oncology, ${ }^{5}$ Radiology, and ${ }^{6}$ Radiation Oncology, \\ Chung Shan Medical University Hospital; ${ }^{7}$ School of Medicine, China Medical University; and ${ }^{8}$ Department \\ of Neurosurgery, China Medical University Hospital, Taichung, Taiwan
}

Object. Most cases of tumor-related hemifacial spasm (HFS) are treated by open surgery. The authors report the effects of Gamma Knife surgery (GKS) on benign tumor-related HFS at a mean follow-up time of 84 months.

Methods. Between 2000 and 2011, 6 patients (5 women and 1 man) harboring single tumors of the cerebellopontine angle (4 meningiomas and 2 vestibular schwannomas [VSs]) and experiencing HFS underwent GKS as a primary treatment. The mean age of the patients at the time of radiosurgery was 52.7 years (range 45-60 years).

The patients' tumors lay within the radiosurgical target area. In the 4 cases of meningioma, the mean radiosurgical treatment volume was $5.3 \mathrm{~cm}^{3}$ (range $1.2-9.6 \mathrm{~cm}^{3}$ ), and the mean radiosurgical tumor margin dose was $14.1 \mathrm{~Gy}$ (range 12-18 Gy); in the 2 cases of VS, the treatment volume was $2.5 \mathrm{~cm}^{3}$ in 1 patient and $11.2 \mathrm{~cm}^{3}$ in the other, and the margin doses were 11.5 and 12 Gy, respectively. The mean duration of HFS symptoms was 15.5 months (range 3-36 months).

Results. The mean follow-up period was 84 months (range 40-110 months). Overall, 4 (66\%) of the 6 patients experienced complete relief from HFS without medication after GKS and 1 patient obtained a good outcome. The mean time for improvement to be realized was 12.6 months (range 3-24 months). Only 1 patient failed to experience relief from HFS, and coincidentally, the tumor did not shrink in that case. In all 6 patients (100\%), tumor growth was controlled at a mean follow-up of 56 months after GKS: in 5 patients the tumor had decreased in size and in the other patient the tumor size remained unchanged. No new neurological deficit was noted after GKS, and 1 patient with facial numbness reported improvement after tumor shrinkage.

Conclusions. Gamma Knife surgery appears to be effective in treating benign tumor-related HFS and in controlling tumor growth. A reduction in tumor volume is related to spasm improvement. Although a time latency for spasm relief is associated with GKS, minimal side effects are expected. (http://thejns.org/doi/abs/10.3171/2012.7.GKS12999)

\section{KEY WoRdS • acoustic neuroma}

OST cases of HFS are caused by a vascular loop that compresses the root exit zone of the facial nerve where it emerges from the brainstem.
Some rare causes of HFS, such as tumors and vascular malformations, have also been identified. Authors of several large case series have reported that symptomatic HFS resulting from mass lesions occurs infrequently, in $0.4 \%-0.8 \%$ of cases. . $^{5,6,13,20,22}$

Most cases of tumor-related HFS are treated satisfactorily by open resection of the tumor alone or combined with vascular decompression. ${ }^{5,6,9,12,13,15,16,20}$ Radiosurgery is now used successfully to treat brain tumors related to hyperfunction of the trigeminal nerve. ${ }^{7,18,19,23}$ Since the

Abbreviations used in this paper: $\mathrm{CPA}=$ cerebellopontine angle; GKS = Gamma Knife surgery; HFS = hemifacial spasm; VS = vestibular schwannoma. incidence of tumor-related HFS is very low, only a few cases treated with surgery or radiosurgery have been reported..$^{8,10,17}$ In the present report we describe outcomes in 6 patients treated by GKS for tumor-related HFS with a mean follow-up of 84 months.

\section{Methods}

\section{Patient Population}

Between 2000 and 2011, 6 patients (5 women and 1 man) with benign tumor-related HFS were treated with the Leksell Gamma Knife (Elekta AB) at our institution. The mean age of the patients at the time of radiosurgery was 52.7 years (range $45-60$ years). Prior to radiosurgery, the patients had experienced continuous discomfort, with mild-to-moderate spasm as part of the constellation of tumor-related symptoms. All patients underwent GKS as 


\section{Gamma Knife surgery for tumor-related hemifacial spasm}

the primary treatment; 3 patients had associated symptoms of hearing impairment or loss, and 1 had trigeminal nerve pain and abducent nerve palsy. The median duration of HFS before GKS was 15.5 months (range 3-36 months). The follow-up period ranged from 40 to 110 months (median 84 months). Patient characteristics in this group are summarized in Table 1.

\section{Radiosurgical Technique}

In all 6 cases the Leksell stereotactic coordinate frame (Elekta $A B$ ) was applied after the patient had received a local anesthetic agent supplemented with a mild sedative. Stereotactic Gd-enhanced MR imaging, in which $1-\mathrm{mm}$ slice intervals were obtained with volume acquisition, was performed during radiosurgery to determine target coordinates and for dose planning. A 201-source cobalt Gamma Knife unit was used for radiosurgery. The radiation volume was determined and shaped to the tumor margin in all 6 patients by using an average of 14 isocenters (range 8-23 isocenters). In the 4 cases of meningioma, the mean radiosurgical treatment volume was $5.3 \mathrm{~cm}^{3}$ (range $1.2-9.6 \mathrm{~cm}^{3}$ ), and the mean radiosurgical tumor margin dose was $14.1 \mathrm{~Gy}$ (range 12-18 Gy); in the 2 cases of VS, the radiation volume was 2.5 $\mathrm{cm}^{3}$ in 1 patient and $11.8 \mathrm{~cm}^{3}$ in the other, and the margin doses were 11.5 and $12 \mathrm{~Gy}$, respectively.

\section{Clinical Assessments}

We subdivided clinical outcomes into 4 categories: excellent, good, fair, and poor. Complete spasm relief after GKS without the use of any medication was defined as an excellent outcome. Patients whose relief from spasm intensity or frequency was more than $90 \%$ were considered to have a good outcome. Patients with partial spasm relief ( $>50 \%-90 \%$ pain relief) were considered to have a fair outcome. No spasm relief or less than $50 \%$ relief was considered a poor outcome.

\section{Results}

The follow-up period ranged from 40 to 110 months (mean 84 months). The outcomes of spasm and other cranial nerve defects are detailed in Table 1. Overall, 4 $(66.6 \%)$ of the 6 patients experienced excellent outcomes and 1 patient (16.7\%) had a good outcome without medication after GKS. Spasm improvement occurred at a mean follow-up time of 12.6 months (range 3-24 months). One patient $(16.7 \%)$ had a poor outcome.

Follow-up MR images showed control of tumor growth in all 6 patients (100\%) at a mean of 84 months after GKS. In 5 patients (83\%) the tumor was smaller than it had been at the time of GKS; all 5 patients eventually experienced spasm improvement (Figs. 1 and 2).

One patient experienced relief from trigeminal nerve pain and excellent spasm relief simultaneously without any improvement in her abducent nerve palsy. The improvements were associated with tumor shrinkage. Three patients with hearing impairment before GKS did not experience an improvement in hearing function.

\section{Discussion}

Most cases of HFS are believed to be caused by vascular compression, but in rare cases, HFS can be caused by tumors. In our experience thus far, cases of tumor-related HFS constituted $2 \%$ of all meningiomas and $1.8 \%$ of VSs treated by GKS. In a group of 1642 patients with HFS who underwent microsurgery, Han et al. ${ }^{6}$ reported that 7 patients $(0.4 \%)$ harbored tumors. Nagata et al. ${ }^{16}$ reported that tumors constituted $2.6 \%$ of their total series of 158 patients. Miyazaki and colleagues ${ }^{15}$ noted that only $4(0.3 \%)$ of 1310 patients with HFS harbored CPA tumors. Kobata et al. ${ }^{12}$ reported that tumors were found in only $7(0.7 \%)$ of 997 patients with HFS. Recently Han and associates ${ }^{5}$ reported a large series of patients who underwent microsurgery for HFS; those authors found 55 tumors $(0.8 \%)$ in 6910 cases. Lee et al. ${ }^{13}$ reported 9 patients $(0.4 \%)$ with tumors among 2050 patients with HFS. In patient groups treated with surgery for tumors, Chang et al. ${ }^{3}$ stated that $2(3 \%)$ of 65 intracranial meningiomas presented with HFS, and Samii and Matthies ${ }^{20}$ noted that $4(0.4 \%)$ of 1000 patients with VSs presented with HFS. In groups of patients who underwent radiosurgery, Iwai et al. ${ }^{8}$ found that facial spasm occurred in $6 \%$ of the patients. There is another subgroup of patients with newly developed HFS after radiosurgery for VSs. Pollock ${ }^{18}$ reported that $2(6.7 \%)$ of 30 enlarged VSs and $2 \%$ of 337 patients who underwent radiosurgery developed new HFS.

TABLE 1: Clinical characteristics and outcomes of GKS in 6 patients*

\begin{tabular}{ccccccccccc}
\hline $\begin{array}{c}\text { Case } \\
\text { No. }\end{array}$ & $\begin{array}{c}\text { Age (yrs), } \\
\text { Sex }\end{array}$ & $\begin{array}{c}\text { Tumor } \\
\text { Type }\end{array}$ & $\begin{array}{c}\text { Duration of HFS } \\
\text { Pre-GKS (mos) }\end{array}$ & $\begin{array}{c}\text { Rad Vol } \\
\left(\mathrm{cm}^{3}\right)\end{array}$ & $\begin{array}{c}\text { Margin } \\
\text { Dose (Gy) }\end{array}$ & $\begin{array}{c}\text { Onset of Improv/ } \\
\text { Improv Gone (mos) }\end{array}$ & $\begin{array}{c}\text { Outcome/ } \\
\text { New Deficits }\end{array}$ & $\begin{array}{c}\text { Tumor Vol } \\
\text { Change }\end{array}$ & $\begin{array}{c}\text { Other } \\
\text { Deficits }\end{array}$ & $\begin{array}{c}\text { FU Time } \\
\text { (mos) }\end{array}$ \\
\hline 1 & $60, \mathrm{~F}$ & men & 36 & 9.6 & 13.4 & $12 / 18$ & E/- & $\downarrow$ & TNP, ANP & 110 \\
2 & $60, \mathrm{~F}$ & men & 36 & 5.3 & 18 & $18 / 60$ & E/- & $\downarrow \downarrow \downarrow$ & HA, tinnitus & 105 \\
3 & $51, \mathrm{~F}$ & VS & 11 & 2.5 & 11.5 & $-/-$ & $\mathrm{P}-$ & $\mathrm{NC}$ & $\mathrm{HI}$, tinnitus & 85 \\
4 & $50, \mathrm{~F}$ & men & 3 & 1.2 & 13 & $3 / 3$ & $\mathrm{E} /-$ & $\downarrow \downarrow$ & $\mathrm{HA}, \mathrm{FN}$ & 74 \\
5 & $45, \mathrm{~F}$ & men & 4 & 5.3 & 12 & $6 /-$ & $\mathrm{G} /-$ & $\downarrow$ & $\mathrm{HI}$ & 75 \\
6 & $50, \mathrm{M}$ & VS & 3 & 11.8 & 12 & $24 / 36$ & E/- & $\downarrow \downarrow \downarrow$ & $\mathrm{HL}$ & 40 \\
\hline
\end{tabular}

* ANP = abducent nerve palsy; $E$ = excellent; $F N=$ facial numbness; $F U=$ follow up; $G=$ good; $H A$ = headache; $H \mathrm{H}=$ hearing impairment; $H L=$ hearing loss; Improv = Improvement; men = meningioma; NC = no change; $P=$ poor; Rad = radiation; TP = trigeminal nerve pain; $\downarrow=25 \%-50 \%$ volume reduction; $\downarrow \downarrow=51 \%-75 \%$ volume reduction; $\downarrow \downarrow \downarrow=$ more than $75 \%$ volume reduction; $-=$ not applicable. 

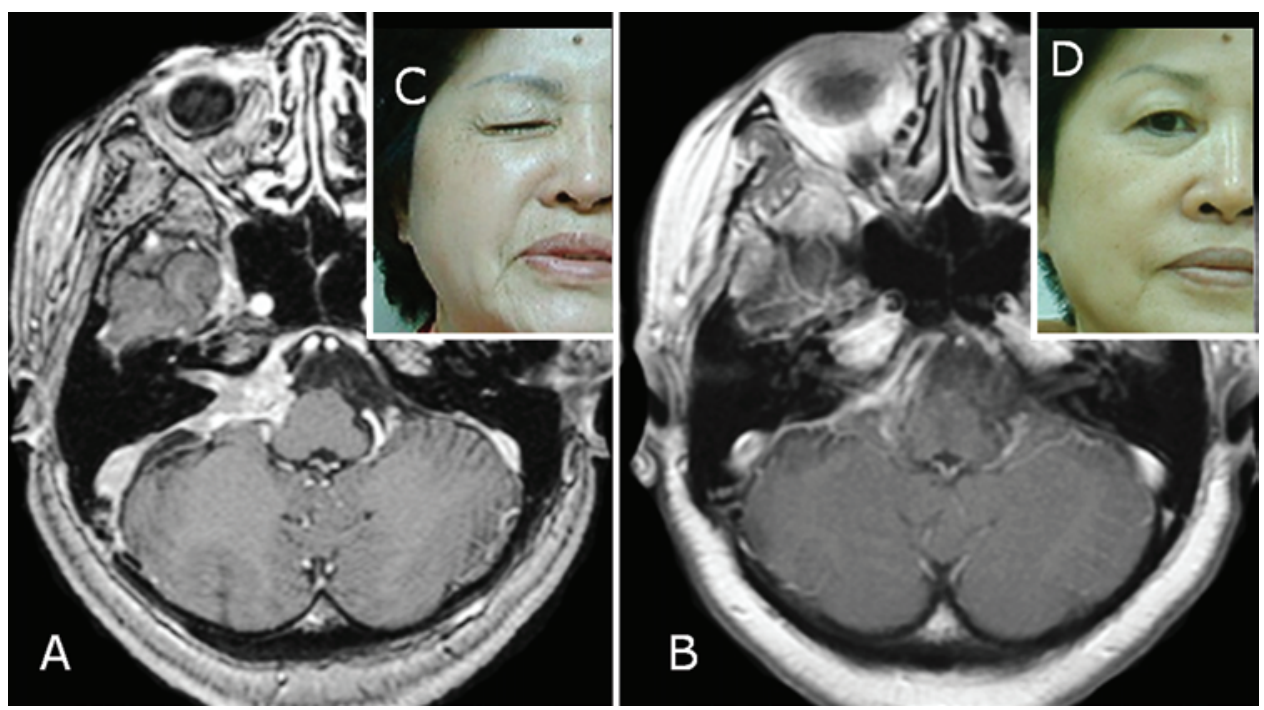

FiG. 1. A: Axial enhanced MR image obtained before GKS in a 60-year-old woman who harbored a meningioma. B: Marked shrinkage of the tumor 8 years after GKS. C: Photograph showing the patient's HFS before GKS. D: Photograph showing complete relief from HFS 5 years post-GKS.

Régis et al. ${ }^{19}$ noted HFS in $3 \%$ of their patients with VSs following treatment with GKS.

\section{Mechanism of Spasm Relief After Microsurgery and Radiosurgery}

The most common cause of HFS is compression of the nerve root by a vascular loop. Only a few cases of compression include tumors, cysts, or vascular malformations as the causative agent. esis is that tumors induce local compression of the facial nerve root exit zone. According to a few reports on large tumors distal to the facial nerve, vascular compression is a reasonable explanation for the incidence of HFS. ${ }^{2}$ Samii and Matthies ${ }^{20}$ demonstrated that small VSs and cranial nerve vascular loop compression coexist intraoperatively. An explanation for the favorable result achieved using microsurgery may be that the tumor debulking achieved with resection rapidly relieves pressure on the facial nerve root. ${ }^{20}$ As for radiosurgery, we observed that in all cases of improvement there was decreased tumor size. Two patients experienced cessation of spasms 30 and 48 months after tumor shrinkage. Pollock ${ }^{18}$ reported the occurrence of new facial spasm due to tumor enlargement in 6 patients 13-26 months (median 20 months) after radiosurgery. This finding provides evidence that tumor size is directly related to facial spasm. Moreover, we also observed that 2 patients experienced spasm relief before marked shrinkage of the tumor volume, and in 2 other patients the time latency of spasm improvement lasted as long as 1.5 years. Since the initial improvement in spasm occurred earlier than tumor shrinkage in these 2 patients, the mechanisms of spasm relief induced by GKS for HFS may be similar to those for idiopathic trigeminal neuralgia. Radiation-induced blockage of the paroxysmal ephaptic transmission in idiopathic trigeminal neuralgia may serve as an explanation for the relief from HFS after GKS. Fraioli et al. ${ }^{4}$ reported preliminary results of treat- ment of idiopathic HFS using radiosurgery or stereotactic hypofractionated radiotherapy and showed that a low radiation dose $(8 \mathrm{~Gy})$ directed to the facial nerve improved HFS. Kida et al. ${ }^{10}$ observed improvement in 5 of 7 pa-
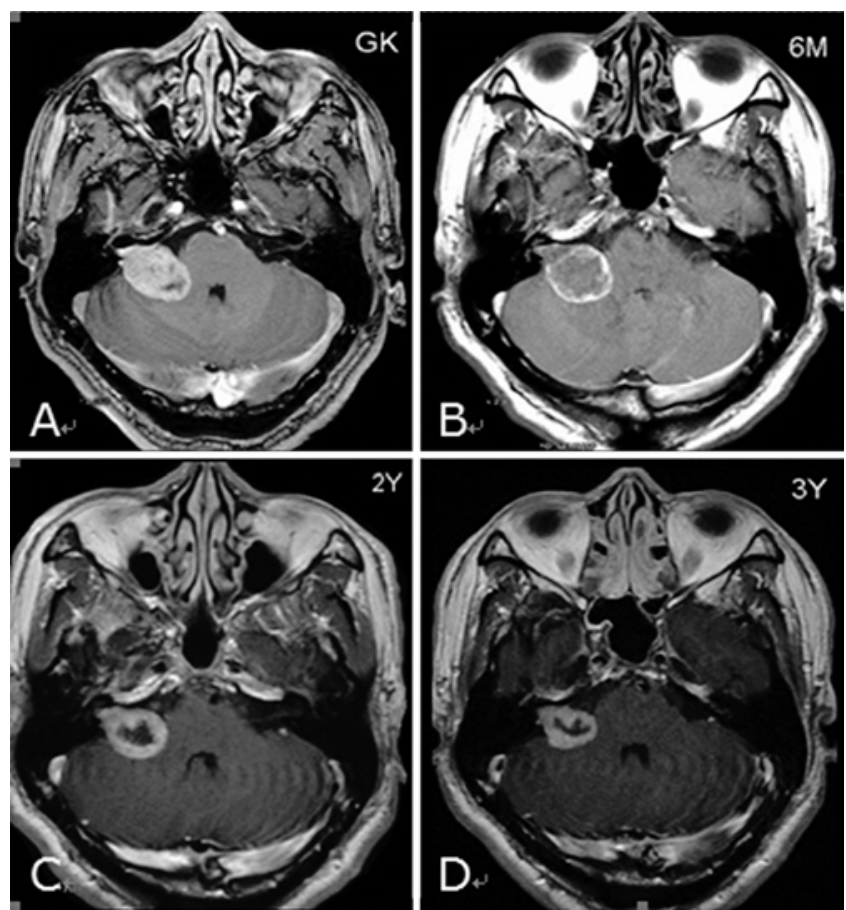

Fig. 2. Magnetic resonance images. A: An enhanced image obtained in a 45-year-old man before GKS showing a VS (volume 11.8 $\left.\mathrm{cm}^{3}\right)$. B: Despite the fact that there is no shrinkage of tumor 6 months post-GKS, there is a loss of central enhancement in the tumor region. C: Evidence of tumor shrinkage (volume $6 \mathrm{~cm}^{3}$ ) 2 years after GKS. The patient's HFS was markedly improved but had not resolved completely. D: Further shrinkage of tumor (volume $3.9 \mathrm{~cm}^{3}$ ). The patient's HFS disappeared 3 years post-GKS. 


\section{Gamma Knife surgery for tumor-related hemifacial spasm}

tients with facial or trigeminal nerve hyperfunction, despite the fact that tumor shrinkage was confirmed in only two patients. Peker and coworkers ${ }^{17}$ observed complete disappearance of facial spasm 12 months after a VS was treated by GKS with 13 Gy delivered to the tumor margin, despite the fact that the tumor volume remained the same at the 22-month follow-up. That case indicates that GKS may be an option for tumor-related HFS.

\section{Outcomes of Microsurgery and Radiosurgery}

Tumor removal is by far the most effective means of relieving tumor-induced HFS in patients who are able to undergo such a procedure safely. Unfortunately, due to the rarity of tumor-induced HFS, only a handful of case reports have been published (Table 2). Of 7 patients in whom a tumor was removed, $6(86 \%)$ experienced total relief of pain, as reported by Han et al. ${ }^{6}$ Samii and Matthies ${ }^{20}$ demonstrated excellent long-term results and freedom from spasm at a mean follow-up time of 9 years in 4 patients with VSs. Nagata et al. ${ }^{16}$ noted excellent postoperative recovery after resection of benign tumors in the posterior fossa in their 4 patients $(100 \%)$. Iwai et al. ${ }^{8}$ reported 2 cases, in which one patient had undergone microsurgery alone and the other patient had microsurgery followed by radiosurgery for residual tumor. Both patients obtained freedom from HFS.

In the literature, there are only 2 published cases of benign tumors associated with HFS that were treated by radiosurgery. Peker et al. ${ }^{17}$ described a case of VS with disappearance of spasm. Kida and colleagues ${ }^{10}$ reported another case involving an epidermoid cyst; in that study the patient also obtained freedom from HFS.

Morbid conditions related to cranial nerves, such as new facial paresis or numbness, are rarely seen in patients who have undergone radiosurgery for skull base tumors. Similar results were observed in our small patient group harboring VSs or CPA meningiomas. In patients treated by microsurgery, transient or permanent facial paresis is relatively high: $9(10 \%)$ of 86 cases have been noted, and other cranial nerve injuries have also been reported (Table 2).

As to the onset of improvement, most patients treated by radiosurgery experienced improvement in association with tumor shrinkage, although there was a lag phase of 3-24 months. In patients treated by microsurgery, most patients experienced immediate improvement.

\section{Conclusions}

Gamma Knife surgey can be effective in treating tumor-related HFS and controlling tumor growth, especially in cases of CPA meningiomas and VSs. Although a lag phase for spasm relief exists, minimal side effects are expected.

\section{Disclosure}

The authors report no conflict of interest concerning the materials or methods used in this study or the findings specified in this paper.

Author contributions to the study and manuscript preparation include the following. Conception and design: Huang, Chuang. Acquisition of data: Chuang, Tu. Analysis and interpretation of data: Chang, Chuang. Drafting the article: Huang, Chang. Critically revising the article: all authors. Reviewed submitted version of manuscript: all authors. Approved the final version of the manuscript on behalf of all authors: Huang. Statistical analysis: Chang, Chuang, Tu, Liu. Administrative/technical/material support: Chuang, Liu. Study supervision: Huang.

TABLE 2: Microsurgical and radiosurgical cases in the treatment of CPA tumor-related HFS*

\begin{tabular}{|c|c|c|c|c|c|c|}
\hline Authors \& Year & $\begin{array}{c}\text { No. of } \\
\text { Patients }\end{array}$ & $\begin{array}{l}\text { No. of Patients Stratified } \\
\text { by Tumor Pattern }\end{array}$ & $\begin{array}{l}\text { No. of Patients Stratified } \\
\text { by Type of Surgery }\end{array}$ & $\begin{array}{l}\text { Follow-Up } \\
\text { (mos) }\end{array}$ & $\begin{array}{l}\text { No. of Patients Stratified } \\
\text { by HFS Outcome }\end{array}$ & $\begin{array}{l}\text { No. of Patients Stratified } \\
\text { by Complication }\end{array}$ \\
\hline $\begin{array}{l}\text { Miyazaki et al., 1983, } \\
1987\end{array}$ & 2 & 1 men, $1 \mathrm{EC}$ & MS & 8,16 & 2 disappeared & $1 \mathrm{HL}, 1 \mathrm{FP}, 1 \mathrm{HO}$ \\
\hline Nagata et al., 1992 & 4 & $1 \mathrm{EC}, 2$ men, $1 \mathrm{VS}$ & MS & NA & 4 disappeared & $1 \mathrm{FP}$ \\
\hline $\begin{array}{l}\text { Samii \& Matthies, } \\
\quad 1995\end{array}$ & 4 & $4 \mathrm{VS}$ & MS & 108 & 4 disappeared & $1 \mathrm{FP}$ \\
\hline Kobata et al., 2002 & 2 & $2 \mathrm{EC}$ & MS & 150 & 2 good & $2 \mathrm{HI}, 1 \mathrm{FN}, 1 \mathrm{ANP}$ \\
\hline Iwai et al., 2003 & 2 & 2 men & $1 \mathrm{MS}, 1 \mathrm{MS}+\mathrm{RS}$ & NA & 2 disappeared & $1 \mathrm{FP}$ \\
\hline Peker et al. 2004 & 1 & $1 \mathrm{VS}$ & RS & 22 & 1 disappeared & none \\
\hline Kida et al., 2006 & 1 & $1 \mathrm{EC}$ & RS & NA & 1 disappeared & none \\
\hline Barajas et al., 2009 & 1 & $1 \mathrm{~L}$ & MS & NA & 1 disappeared & none \\
\hline Han et al., 2009 & 7 & $3 \mathrm{EC}, 1 \mathrm{VS}, 2 \mathrm{~L}, 1 \mathrm{AC}$ & MS & NA & $\begin{array}{l}6 \text { disappeared (1 re- } \\
\text { peated MVD) }\end{array}$ & $1 \mathrm{FP}, 1 \mathrm{HL}$ \\
\hline Han et al., 2010 & 55 & $41 \mathrm{EC}, 7$ men, $7 \mathrm{Vs}$ & MS & NA & 43 disappeared & $2 \mathrm{FP}, 6 \mathrm{HI}, 2 \mathrm{HO}$ \\
\hline Lee et al., 2010 & 9 & 5 men, 2 VS, 2 EC & MS & NA & 7 disappeared & $2 \mathrm{FP}$ \\
\hline current series & 6 & 4 men, 2 VS & RS & 84 (mean) & $\begin{array}{l}4 \text { disappeared, } 1 \mathrm{im}- \\
\text { proved }\end{array}$ & none \\
\hline
\end{tabular}

\footnotetext{
* $\mathrm{AC}=$ arachnoid cyst; $\mathrm{EC}=$ epidermoid cyst; $\mathrm{FP}=$ facial palsy; $\mathrm{HO}=$ hoarseness; $\mathrm{L}=$ lipoma; $\mathrm{MS}=$ microsurgery; $\mathrm{MVD}=$ microvascular decompres-
} sion; NA = not analyzed; RS = radiosurgery. 


\section{References}

1. Barajas RF Jr, Chi J, Guo L, Barbaro N: Microvascular decompression in hemifacial spasm resulting from a cerebellopontine angle lipoma: case report. Neurosurgery 63:E815E816, 2008

2. Bhayani R, Goel A: Occipital falcine meningioma presenting with ipsilateral hemifacial spasm: a case report. Br J Neurosurg 10:603-605, 1996

3. Chang CG, Cho DY, Lee JC, Yang DY: [Intracranial meningiomas - 5 year analysis.] Zhonghua Yi Xue Za Zhi (Taipei) 43:321-330, 1989 (Chinese)

4. Fraioli MF, Moschettoni L, Fraioli C, Strigari L: Treatment of idiopathic hemifacial spasm with radiosurgery or hypofractionated stereotactic radiotherapy: preliminary results. Minim Invasive Neurosurg 53:34-36, 2010

5. Han H, Chen G, Zuo H: Microsurgical treatment for 55 patients with hemifacial spasm due to cerebellopontine angle tumors. Neurosurg Rev 33:335-340, 2010

6. Han IB, Chang JH, Chang JW, Huh R, Chung SS: Unusual causes and presentations of hemifacial spasm. Neurosurgery 65:130-137, 2009

7. Huang CF, Tu HT, Liu WS, Lin LY: Gamma Knife surgery for trigeminal pain caused by benign brain tumors. J Neurosurg 109 Suppl:154-159, 2008

8. Iwai Y, Yamanaka K, Nakajima H: Hemifacial spasm due to cerebellopontine angle meningiomas - two case reports. Neuro Med Chir (Tokyo) 41:87-89, 2001

9. Iwai Y, Yamanaka K, Shiotani M, Uyama T: Radiosurgery for acoustic neuromas: results of low-dose treatment. Neurosurgery 53:282-288, 2003

10. Kida Y, Yoshimoto M, Hasegawa T, Fujitani S: [Radiosurgery of epidermoid tumors with gamma knife: possiblility of radiosurgical nerve decompression.] No Shinkei Geka 34:375381, 2006 (Jpn)

11. Kiley MA, Voyvodic F, Burns RJ: An unusual cause of hemifacial spasm. J Clin Neurosci 6:349-351, 1999

12. Kobata H, Kondo A, Iwasaki K: Cerebellopontine angle epidermoids presenting with cranial nerve hyperactive dysfunction: pathogenesis and long-term surgical results in $30 \mathrm{pa}-$ tients. Neurosurgery 50:276-286, 2002

13. Lee SH, Rhee BA, Choi SK, Koh JS, Lim YJ: Cerebellopontine angle tumors causing hemifacial spasm: types, incidence, and mechanism in nine reported cases and literature review. Acta Neurochir (Wien) 152:1901-1908, 2010

14. Miyazaki S, Fukushima T: [Cerebellopontile angle epidermoid presenting as hemifacial spasm.] No To Shinkei 35:951-955, 1983 (Jpn)

15. Miyazaki S, Fukushima T, Nagai A, Tamagawa T: [CP angle meningioma presenting as hemifacial spasm.] No Shinkei Geka 15:683-686, 1987 (Jpn)

16. Nagata S, Matsushima T, Fujii K, Fukui M, Kuromatsu C: Hemifacial spasm due to tumor, aneurysm, or arteriovenous malformation. Surg Neurol 38:204-209, 1992

17. Peker S, Ozduman K, Kiliç T, Pamir MN: Relief of hemifacial spasm after radiosurgery for intracanalicular vestibular schwannoma. Minim Invasive Neurosurg 47:235-237, 2004

18. Pollock BE: Management of vestibular schwannomas that enlarge after stereotactic radiosurgery: treatment recommendations based on a 15 year experience. Neurosurgery 58:241248, 2006

19. Régis J, Pellet W, Delsanti C, Dufour H, Roche PH, Thomassin $\mathrm{JM}$, et al: Functional outcome after gamma knife surgery or microsurgery for vestibular schwannomas. J Neurosurg 97: 1091-1100, 2002

20. Samii M, Matthies C: Acoustic neurinomas associated with vascular compression syndromes. Acta Neurochir (Wien) 134:148-154, 1995

21. Shenouda EF, Moss TH, Coakham HB: Cryptic cerebellopontine angle neuroglial cyst presenting with hemifacial spasm. Acta Neurochir (Wien) 147:787-789, 2005

22. Sprik C, Wirtschafter JD: Hemifacial spasm due to intracranaial tumor. An international survey of botulinum toxin investigators. Ophthalmology 95:1042-1045, 1988

23. Young RF, Vermeulen SS, Grimm P, Blasko J, Posewitz A: Gamma Knife radiosurgery for treatment of trigeminal neuralgia: idiopathic and tumor related. Neurology 48:608-614, 1997

Manuscript submitted May 15, 2012.

Accepted July 2, 2012.

Portions of this work were presented in abstract form at the 16th International Meeting of the Leksell Gamma Knife Society, Sydney, Australia, March 25-29, 2012.

Please include this information when citing this paper: DOI: 10.3171/2012.7.GKS12999.

Address correspondence to: Chuan-Fu Huang, M.D., Department of Neurosurgery, China Medical University Hospital, 2 Yu Der Road, Taichung 402, Taiwan. email: gkf0218@yahoo.com.tw. 